MRS Advances (C) 2017 Materials Research Society

DOI: 10.1557/adv.2017.323

\title{
Disodium Pyridine Dicarboxylate vs Disodium Terephthalate as Anode Materials for Organic Na Ion Batteries: Effect of Molecular Structure on Voltage from the Molecular Modeling Perspective
}

Yingqian Chen ${ }^{1}$, Johann Lüder ${ }^{1}$, and Sergei Manzhos ${ }^{1 *}$

${ }^{1}$ Department of Mechanical Engineering, Faculty of Engineering, National University of Singapore, Block EA \#07-08, 9 Engineering Drive 1, Singapore 117576

*E-mail:mpemanzh@nus.edu.sg

\begin{abstract}
Using Density Functional Theory based modeling, we compare sodium attachment to disodium terephthalate $\left(\mathrm{Na}_{2} \mathrm{Tph}\right)$ and a related molecule disodium pyridine dicarboxylate $\left(\mathrm{Na}_{2} \mathrm{PDC}\right)$. We predict that substitution of the $\mathrm{Na}_{2} \mathrm{Tph}$ 's aromatic ring with pyridine will lead to an increased voltage by about $0.4 \mathrm{~V}$ vs $\mathrm{Na}_{2+\mathrm{x}} \mathrm{Tph}$ up to $\mathrm{Na}_{2+1} \mathrm{PDC}$ and a similar voltage to the terephthalate between $\mathrm{Na}_{2+1} \mathrm{PDC}$ and $\mathrm{Na}_{2+2} \mathrm{PDC}$, i.e. a two-plateau behavior vs. a single plateau for $\mathrm{Na}_{2+\mathrm{x}} \mathrm{Tph}$.
\end{abstract}

\section{INTRODUCTION}

Organic secondary batteries are promising as they can be scalable and sustainable $[1,2]$. They have attracted attention especially for use in sodium ion batteries, as they can easier accommodate the large ionic radius of $\mathrm{Na}^{+}$than inorganic materials [3]. Organic $\mathrm{Na}$ ion batteries would allow for full use of sustainability and scalability of both organic materials and of extremely abundant $\mathrm{Na}$. Contrary to Li ion batteries where good anode solutions such as graphite or silicon exist, new anode materials must be designed for $\mathrm{Na}$ ion batteries, as graphite and silicon are not electrochemically active for $\mathrm{Na}$.

Lithium and sodium terephthalates have been shown to be effective organic anode materials for lithium and sodium ion batteries, respectively [4-6]. Specifically, disodium terephthalate $\left(\mathrm{Na}_{2} \mathrm{Tph}\right)$ has been studied in several experimental works $[5,6]$ and showed an ideal voltage for $\mathrm{Na}$ ion batteries of $0.2-0.3 \mathrm{~V}\left(\mathrm{vs} . \mathrm{Na} / \mathrm{Na}^{+}\right)$, a high capacity of about $250 \mathrm{mAh} \mathrm{g}^{-1}$ and a decent cycling rate and cycling life performance in experimental batteries [6]. However, for practical use, cycle rate and life should be improved.

$\mathrm{Ab}$ initio models of $\mathrm{Na}$ attachment to the $\mathrm{Na}_{2} \mathrm{Tph}$ molecule and $\mathrm{Na}$ insertion into the $\mathrm{Na}_{2} \mathrm{Tph}$ crystal have been reported $[7,8]$. These models explained the sodiation mechanism by occupancy of unoccupied orbitals or the conduction band by valence electrons of the inserted $\mathrm{Na}$. It was also understood that $\mathrm{Na}$ atoms would segregate into $\mathrm{Na}_{2+2} \mathrm{Tph}$ resulting in a flat, singleplateau voltage profile, in agreement with experiments [6]. $\mathrm{Na}_{2} \mathrm{Tph}$ possesses a rather high band gap which results in low electronic conductance. The segregation might also limit the kinetics of sodiation.

Disodium pyridine dicarboxylate $\left(\mathrm{Na}_{2} \mathrm{PDC}\right)$ which is obtained by substitution of the $\mathrm{Na}_{2}$ Tph's aromatic ring with pyridine, is expected to improve conductance. This potential anode material remains unstudied. Here, we present a preliminary ab initio investigation of the mechanism of $\mathrm{Na}$ attachment to the $\mathrm{Na}_{2} \mathrm{PDC}$ molecule and, based on available results for the $\mathrm{Na}_{2} \mathrm{Tph}$ molecule and crystal, make an estimate of the expected voltage curve of $\mathrm{Na}_{2+} \mathrm{PDC}$. 


\section{METHODS}

Molecular structures of $\mathrm{Na}_{2} \mathrm{Tph}$ and of $\mathrm{Na}_{2} \mathrm{PDC}$ including those with additional $\mathrm{Na}$ atoms attached were optimized with the SIESTA code [9] employing Density Functional Theory (DFT) [10]. A $20 \times 20 \times 20 \AA$ box containing one molecule was used for optimization to avoid cross talk between periodic images. Geometries were optimized until the forces on all atoms were below $0.02 \mathrm{eV} / \AA$. The PBE [11] exchange-correlation functional and a DZP (double- $\zeta$ polarized) basis set were used. The basis set was optimized to reproduce the cohesive energies of $\mathrm{C}, \mathrm{Na}$ and $\mathrm{N}$, while it was generated with the parameter PAO EnergyShift of $0.01 \mathrm{Ry}$ for $\mathrm{O}$ and $\mathrm{H}$. A plane wave energy cutoff of 100 Ry was used for the Fourier expansion of the density. An electronic temperature of $500 \mathrm{~K}$ was set to speed up the convergence. The Brillouin zone was sampled at the $\Gamma$ point. Spin polarization was considered for all systems. We have previously shown that this setup reproduces results obtained with full potential, hybrid functional calculations using larger basis sets [12].

We compute the binding energy per $\mathrm{Na}$ atom $\left(E_{b}\right)$ as

$$
E_{b}=\frac{E\left(N a_{2+x} T p h / P D C\right)-E\left(N a_{2} T p h / P D C\right)-x E(N a)}{x}
$$

where $E\left(N a_{2+x} T p h / P D C\right)$ is the energy of the complex of $x \mathrm{Na}$ atoms attached to the $\mathrm{Na}_{2} \mathrm{Tph}$ or $\mathrm{Na}_{2} \mathrm{PDC}$ molecule, $E\left(\mathrm{Na}_{2} \mathrm{Tph} / \mathrm{PDC}\right)$ is the energy of the molecule before $\mathrm{Na}$ attachment, and $E(\mathrm{Na})$ is the energy of a $\mathrm{Na}$ atom in $b c c \mathrm{Na}$ metal. Voltages are estimated between $x_{1}$ and $x_{2}$ as

$$
V=-\frac{E\left(N a_{2+x_{2}} T p h / P D C\right)-E\left(N a_{2+x_{1}} T p h / P D C\right)-\left(x_{2}-x_{1}\right) E(N a)}{q\left(x_{2}-x_{1}\right)}
$$

where for $x_{1}$ and $x_{2}$, the lowest energy configurations are used (resulting in lowest total energy and lowest $E_{b}$ ). We use $x=1,2,3 . q=1$ is the number of electrons transferred per Na atom.

We perform calculations on single molecules in vacuum. We have previously shown that effects on crystallinity can be significant $[7,8,12,13]$. To estimate the voltage profile which would be observed with the $\mathrm{Na}_{2} \mathrm{PDC}$ crystal, we assume that the effects of crystallinity are similar in $\mathrm{Na}_{2} \mathrm{Tph}$ and $\mathrm{Na}_{2} \mathrm{PDC}$ (as their molecular and crystalline structures are quite similar). Therefore, shifts in the voltages due to the crystal environment are taken to be of the same amount for both molecules. Since this shift is known for $\mathrm{Na}_{2} \mathrm{Tph}$ from reported experimental and theoretical data $[7,8]$, we can align the voltage estimate of $\mathrm{Na}_{2} \mathrm{PDC}$ from single molecule data to the expected profile of the $\mathrm{Na}_{2} \mathrm{PDC}$ crystal.

Density difference maps were computed as the difference of electron densities of $\mathrm{Na}_{2+} \mathrm{PDC}$ and the isolated $\mathrm{Na}_{2} \mathrm{PDC}$ and the $\mathrm{Na}_{\mathrm{x}}$ atom(s) at the geometries assumed in the $\mathrm{Na}_{2+} \mathrm{PDC}$ complex.

\section{RESULTS AND DISCUSSION}

A number of possible configurations for the attachment of one, two, and three sodium atoms to the $\mathrm{Na}_{2} \mathrm{Tph}$ and to the $\mathrm{Na}_{2} \mathrm{PDC}$ molecules were tried. Figure 1 shows the lowest energy 
configurations of the pristine molecules and the attachment of one to three $\mathrm{Na}$ atoms to them, as well as the corresponding $E_{b}$. The left panel of Figure 2 shows the computed voltage curves vs. the number of attached $\mathrm{Na}$ atoms, corresponding to these single-molecule configurations. The right panel of Figure 2 shows the voltage curves predicted for the corresponding crystalline materials vs. the specific capacity. In these curves, we discarded configurations with three attached $\mathrm{Na}$ atoms, which are expected to be severely sterically hindered given the crystal structure [7].

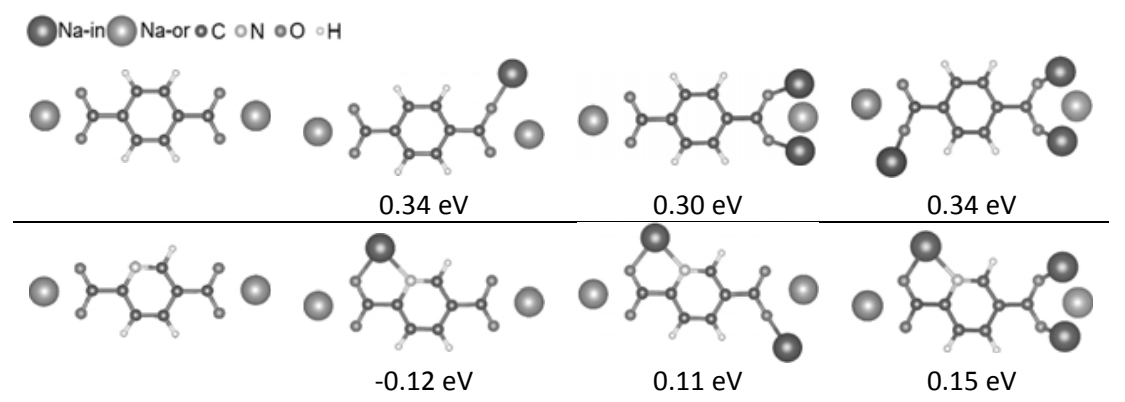

Figure 1. From left to right: Lowest energy configurations of pristine, one, two, and three sodium atoms attached to the $\mathrm{Na}_{2} \mathrm{Tph}$ (top row) and to the $\mathrm{Na}_{2} \mathrm{PDC}$ (bottom row) molecules, together with $E_{b}$ shown below the structures. Visualization here and elsewhere is done in VESTA [14].
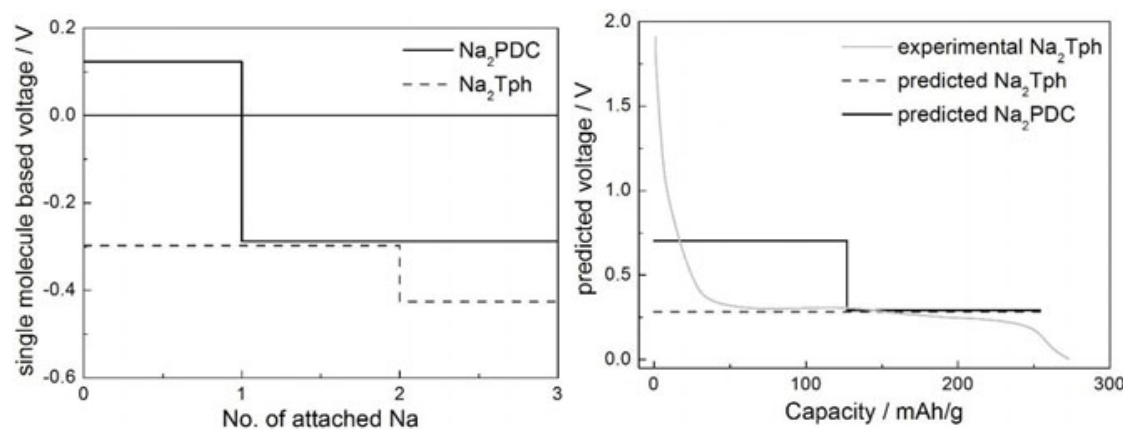

Figure 2. Left: the computed voltages of $\mathrm{Na}_{2} \mathrm{Tph}$ (dashed curve) and $\mathrm{Na}_{2} \mathrm{PDC}$ (solid curve) molecules during $\mathrm{Na}$ attachment. Right: predicted voltage profile of $\mathrm{Na}_{2+} \mathrm{PDC}$ (solid curve) after adjusting for environment effects. The experimental voltage curve of $\mathrm{Na}_{2} \mathrm{Tph}$ at a $\mathrm{C} / 20$ rate (light solid curve) read from Figure 4a of Ref. [6] (to which the computed voltage profile of $\mathrm{Na}_{2} \mathrm{Tph}$ (dashed curve) is calibrated) is also shown.

It follows from Figure 2 that 
(i) Single-molecule calculations predict a flat voltage profile for $\mathrm{Na}_{2+\mathrm{x}} \mathrm{Tph}$, in agreement with experiments [6] and with periodic DFT calculations on crystalline $\mathrm{Na}_{2+x} \mathrm{Tph}$ [7]. That is, the single-molecule calculations correctly predict $\mathrm{Na}$ segregation into fully sodiated $\mathrm{Na}_{2+2} \mathrm{Tph}$. We therefore expect correct calculations also for $\mathrm{Na}_{2+} \mathrm{PDC}$.

(ii) The predicted voltage curve of $\mathrm{Na}_{2+} \mathrm{PDC}$ differs quantitatively and qualitatively from that of $\mathrm{Na}_{2+x} \mathrm{Tph}$. Specifically, the voltage is predicted to be about $0.4 \mathrm{~V}$ higher for half-sodiation, i.e.

$\mathrm{Na}_{2+1} \mathrm{PDC}$ vs. the terephthalate counterpart. Moreover, the voltage curve is predicted to have two plateaus. The first plateau up to half-sodiation is at about $0.7 \mathrm{~V}$ and the second plateau, i.e. from half- to full sodiation, is at about $0.3 \mathrm{~V}$. That is to say, the second plateau (between $\mathrm{Na}_{2+1} \mathrm{PDC}$ and $\mathrm{Na}_{2+2} \mathrm{PDC}$ ) is only slightly higher than the one of $\mathrm{Na}_{2+\mathrm{x}} \mathrm{Tph}$. Because of the higher-voltage of the first plateau, no Na segregation into a fully sodiated phase is expected, contrary to $\mathrm{Na}_{2+\mathrm{x}} \mathrm{Tph}$.

The qualitative and quantitative difference in the voltage profiles of $\mathrm{Na}_{2} \mathrm{Tph}$ and $\mathrm{Na}_{2} \mathrm{PDC}$ is explained by the preferred coordination of the first attached $\mathrm{Na}$ atom to the $\mathrm{N}$ atom in $\mathrm{Na}_{2} \mathrm{PDC}$. Indeed, a Na-N bond is formed as can be seen in the charge density difference plot shown in Figure 3. The formation of the bond with the $\mathrm{N}$ atom, in addition to the bond with the $\mathrm{O}$ atom, leads to a stronger interaction, i.e. stronger $E_{b}$, compared to the attachment of $\mathrm{Na}$ on $\mathrm{Na}_{2} \mathrm{Tph}$ where only the Na-O bond is formed.

Furthermore, the HOMO-LUMO gap of $\mathrm{Na}_{2} \mathrm{PDC}$ computed here is $2.77 \mathrm{eV}$, which is smaller than that of $\mathrm{Na}_{2} \mathrm{Tph}, 2.98 \mathrm{eV}$. This means that the valence electron of $\mathrm{Na}$ will occupy a lower-energy electronic state, which would lead to a higher voltage. The lower gap also means that the electronic conductance will be improved vs. the terephthalate analogue, which is expected to improve the rate performance, as well as to reduce polarization.

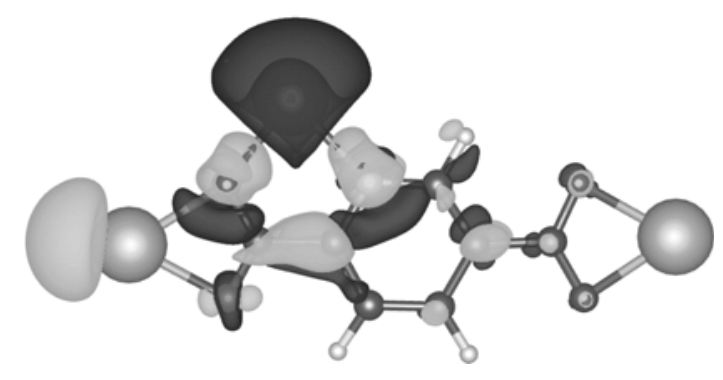

Figure 3. Density difference map showing the formation of a $\mathrm{Na}-\mathrm{N}$ bond, taking $\mathrm{Na}_{2+1} \mathrm{PDC}$ (the second configuration in the bottom row of Figure 1) as an example. Light gray iso-density surfaces show charge accumulation and dark gray surfaces show depletion. The large dark area on top corresponds to the depletion of the valence shell of $\mathrm{Na}$, and accumulation of the density between the $\mathrm{Na}$ and $\mathrm{N} / \mathrm{O}$ atoms (light grey) indicates bond formation.

\section{CONCLUSIONS}

We performed a comparative ab initio study of sodium attachment to disodium terephthalate $\left(\mathrm{Na}_{2} \mathrm{Tph}\right)$ and disodium pyridine dicarboxylate $\left(\mathrm{Na}_{2} \mathrm{PDC}\right)$ molecules and used single-molecule calculations to predict the voltage curve of $\mathrm{Na}_{2+} \mathrm{PDC}$. The voltage curve of 
$\mathrm{Na}_{2+} \mathrm{PDC}$ is predicted to have two plateaus as opposed to a single plateau for $\mathrm{Na}_{2+\mathrm{x}} \mathrm{Tph}$. Between $\mathrm{Na}_{2} \mathrm{PDC}$ and $\mathrm{Na}_{2+1}$ PDC, the voltage is predicted to be about $0.4 \mathrm{~V}$ higher than for $\mathrm{Na}_{2} \mathrm{~T}$ ph $-\mathrm{Na}_{2+1} \mathrm{Tph}$, while between $\mathrm{Na}_{2+1} \mathrm{PDC}$ and $\mathrm{Na}_{2+2} \mathrm{PDC}$, the voltage is predicted to be similar (marginally higher) to that with the terephthalate. This also means that while in $\mathrm{Na}_{2+\mathrm{x}} \mathrm{Tph}$, sodium segregation must occur to the fully sodiated phase, no such segregation is expected for $\mathrm{Na}_{2+\mathrm{x}} \mathrm{PDC}$. The HOMO-LUMO gap of $\mathrm{Na}_{2} \mathrm{PDC}$ is smaller than in $\mathrm{Na}_{2} \mathrm{Tph}$, which must improve electron conductance and charge-discharge kinetics.

Overall, $\mathrm{Na}_{2+} \mathrm{PDC}$ appears to be a promising anode material for organic $\mathrm{Na}$ ion batteries. Compared to the terephthalate, it is expected to result in a lower overall battery voltage (due to a higher $\mathrm{Na}$ insertion potential) but also in an improved rate capability (due to a lower gap and reduced phase segregation).

\section{ACKNOWLEDGMENTS}

This work was supported by the Ministry of Education of Singapore (MOE Tier 2 grant MOE2014-T2-2-006).

\section{REFERENCES}

[1] R. B. Araujo et al., J. Mater. Chem. A, 5 (9), 2017, 4430-4454

[2] D. Larcher and J.-M. Tarascon, Nat. Chem., 7 (1) , 2014, 19-29

[3] O. I. Malyi, T. L. Tan, and S. Manzhos, App. Phys. Express, 6 (2), 2013, 027301

[4] M. Nisula and M. Karppinen, Nano Lett., 16 (2), 2016, 1276-1281

[5] Y. Park et al., Adv. Mat., 24 (26), 2012, 3562-3567

[6] L. Zhao et al., Adv. Energy Mat., 2 (8), 2012, 962-965

[7] M. A. Sk and S. Manzhos, J. Power Sources, 324, 2016, 572-581

[8] M. A. Sk and S. Manzhos, MRS Advances, 1 (53), 2016, 3579-3584

[9] J. M. Soler et al., J. Phys.: Condens. Matter 14 (11), 2002, 2745-2779

[10] W. Kohn and L. J. Sham, Phys. Rev., 140 (4A), 1965, A1133-A1138

[11] J. P. Perdew, K. Burke, and M. Ernzerhof, Phys. Rev. Lett., 77 (18), 1996, 3865-3868

[12] Y. Chen and S. Manzhos, Phys. Chem. Chem. Phys., 18 (3), 2016, 1470-1477

[13] Y. Chen and S. Manzhos, Phys. Chem. Chem. Phys., 18 (13), 2016, 8874-8880

[14] Y. Chen and S. Manzhos, Mater. Chem. Phys., 156, 2015, 180-187 